\title{
CONCERNING PSYCHOLOGIC TESTS IN THE ARMY AND THEIR MEANING FOR THE TEACHER.
}

By J. W. A. Young,

The University of Chicago.

In recent years the assertion has frequently been heard that mental training and mental abilities are "specific," not "general."

"This discipline trains-not general faculties but specialized abilities."

"The following standard of educational values is based upon the doctrine of specific disciplines, supported, we believe, by experimental evidence and general observation. Mathematies, for instance, would be defended on this doctrine for its great specific value in developing ability to reason, to be accurate, etc., in regard to the mathematical elements in the environment."

That one may develop his ability to reason, to be accurate, etc., with respect to mathematical concepts, without in any wise altering his ability to reason, to be accurate, etc., with respect to other concepts, that is, that there exists a separate and closed body of mental processes for the work in the large and varied aggregate that our schoolrooms label "mathematics" and which processes function nowhere else, is a supposition which needs only to be stated to exhibit its absurdity.

When one seeks definite grounds for assertions of the above type, the advocates of specific values are very chary with specific reasons. One meets with "general" assertions that "psychologists have established" this or that, that belief in the functioning of the results of mental training beyond the specific content of the training material is now "discredited," in fact, so thoroughly "exploded" as to be discreditable, but specific proofs or even references thereto are difficult to find.

As a matter of fact, a large body of psychologic experiment of dominating import, is based on just the opposite assumption, namely the assumption that mental abilities are not restricted in their functioning to content of-a specific verbal label, but are of a wide, general range; for example, that the degree of speed and accuracy with which a soldier will comprehend and execute commands on the battlefield will correspond to the degree of speed and accuracy with which he comprehends and executes the direction to draw lines about circles in the testing room.

A most striking instance is found in the tests devised for the U. S. Government by a commission of eminent psychologists and applied to a million and a half men in the army. The tests have recently been made public. ${ }^{3}$

\footnotetext{
1Flexner, A., Education as a Mental Discipline, Atlantic Monthly, April, 1917, p. 458.

${ }^{2}$ Heck, W. H., Mental Discipline and Educational Values, 1912, pp. 163, 162.

"For instance in a pamphlet "Army Mental Tests," printed at Washington, November 22 1918, and now distributed by the Division of Paychology, in an authorized interview published in the New York Times, February 16, 1919, and in a traveling exhibit which was shown in the North-Western University Building, Chicago, Feb. 11-14. The statements below are drawn from these sources.
} 
The tests aimed at determining the man's general mental power and not his specific attainments. Those in charge believed that they achieved this aim.

"The rating a man earns furnishes a fairly reliable index of his ability to learn, to think quickly and accurately, to analyze a situation, to maintain a state of mental alertness, and to comprehend and follow instructions."

The degrees of intelligence were graded as follows:

A. Very superior intelligence. Men of high officer type (when endowed with leadership, etc.).

B. Superior intelligence. Many men of officer type, and a large amount of non-commissioned officer material.

$\mathrm{C}+$. High average intelligence.

C. Average intelligence.

$\mathrm{C}-$. Low average intelligence.

D. Inferior intelligence.

D-. Very inferior intelligence but fit for regular service.

E. Very inferior intelligence and not fit for regular service.

The following are samples of the tests by which these grades were determined. The directions were given orally.

Given:
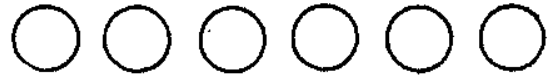

Directions: Make a cross in the second circle and also a figure 1 in the third circle. (Time allowed, five seconds.)

Given:
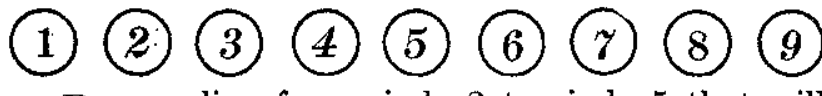

Directions: Draw a line from circle 2 to circle 5 that will pass above circle 3 and below circle 4 .

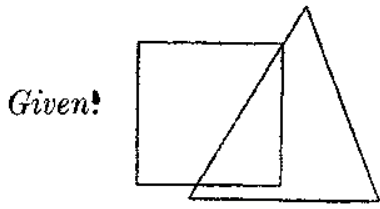

Directions: Make a cross in the space which is in the square and not in the triangle, and also make a figure in the space which is in the triangle and not in the square. (Ten seconds.)

Given:
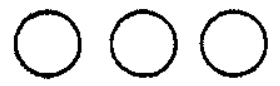

YES NO.

Directions: If a regiment is bigger than a company, then put a cross in the first circle. If not, draw a line under the word "No." (Ten seconds.)

Given:
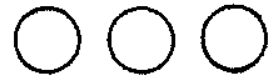

MILITARY GUN CAMP. 
Directions: Make in the first circle, the last letter of the first word; in the second circle, the last letter of the second word, and in the third circle, the third letter of the third word. (Ten seconds.)

\section{Given: 34-79-56-87-68-25-82-47-27-31-64-93-71-41-52-99.}

Directions: Cross out each number that is more than 30 but less than 40. (Fifteen seconds.)

\section{Given: 1-2-3-4-5-6-7-8-9.}

Directions: If 6 is more than 4 then cross out the number 5 , unless 5 is more than 7 , in which case draw a line under the number 6 . (Ten seconds.)

Given: Twenty questions in mental arithmetic, of which the first and last are:

1. How many are forty and six guns?

20. A commission house, which had already supplied 1,897 barrels of apples to a cantonment, delivered the remainder of the stock to 28 mess halls. Of this remainder, each mess hall received 47 barrels. What was the total number of barrels supplied?

(Five minutes allowed to solve the twenty problems.)

Given: If plants are dying for lack of rain you should

Water them.

Ask a florist's advice.

Put fertilizer around them.

Directions: Make a cross before the best answer.

(One and one-half minutes allowed to mark sixteen sentences like the above each with three printed answers.)

Given: $5 \quad 10 \quad 15 \quad 202530$

$$
\begin{array}{llllll}
21 & 18 & 16 & 15 & 12 & 10
\end{array}
$$

Directions: Write the two numbers that should come next in each row.

Given: Order-confusion peace part treaty war enemy.

Directions: Notice the relation between the first two words, and then underline the word in heavy type that is related to the third word in the same way.

Similarly:

Education-ignorance wealth poverty riches health comfort. $10-100$ 1,000 money $10,00020,000$ wealth.

Given: The battle of Lexington was fought in 1620,1775 , $1812,1864$.

Directions: Underline that one of the four last words which makes the truest sentence. 
Similarly: The kilowatt is used in measuring rainfall, windpower, electricity, waterpower.

An eight-sided figure is called a trapezium, scholium, parallelogram, octagon.

How familiar these questions sound to the teacher of mathematies! How akin in substance and in spirit to certain phases of his subject! But they are the phases of which he is least proud; which, indeed, he probably regards as a necessary evil, the scaffolding without which he cannot build his edifice. If any high schools and colleges had said in recent years: "We will forget the valuable content of mathematics, second in widespread usefulness only to the mother tongue, we will make no effort to exhibit to our students its clear cut logic--the model and ideal of all sciences-we will concentrate all our energies on training our students to speed and accuracy in its most rudimentary processes," what a chorus of protest would have arisen! "Useless," "artificial," "mere puzzles," "unrelated to real life," "trains only the most restricted special abilities," would have been heard from all sides. Yet the student from such a school, when called to the army, would have been rewarded by a higher rating in general intelligence, for whatever skill he had acquired through this training. For we are told in no uncertain terms, that the objects of these most specific tests was to measure the most general abilities. Thus it is stated by the Division of Psychology that:

"These tests provide an immediate and reasonably dependable classification of the men according to general intelligence. Their specifie purposes are to aid in the discovery of men whose superior intelligence suggests their consideration for advancement, in forming organizations of uniform mental strength, where such uniformity is desirable, in forming organizations of superior mental strength where such superiority is demanded, in the early recognition of the mentally slow, etc."

The psychologic ratings were given at the outset, and their correctness was promptly put to the test in the work that followed in the military training schools. The verdict was throughout highly gratifying and distinctly confirmed the ratings. The diagrams on page 548 will serve sufficiently as specimens of many such corroboratory outcomes:

So satisfactory have the results of these psychologic tests been that Columbia University has announced its purpose of using such tests in passing upon applications for admission to the university, and that strong efforts are being made to extend these methods to business organizations.

What does all this mean for the teacher of arithmetic, of high school mathematics? Does it mean that much more stress 
should be laid on the most elementary formalism, on extensive and intensive drill in the type of work that psychologists use to test men's general intelligence? Our information as to the nature of the tests and their outcomes is still too fragmentary to furnish definitive answers to these questions.
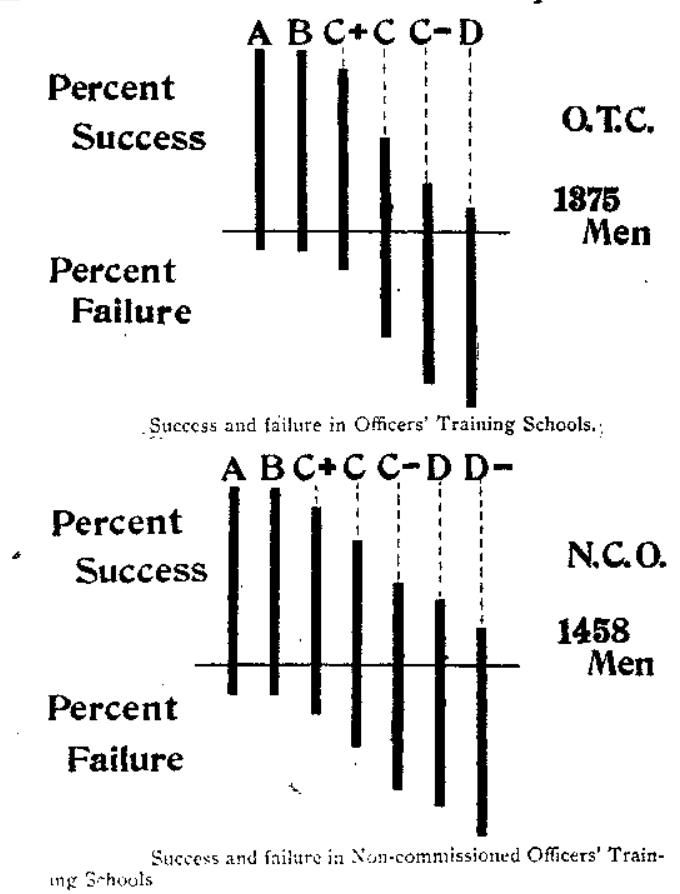

One thing, however, is already evident. No teacher of mathematies who believes that the study of his subject can contribute to the advancement of the pupil's general intelligence and who teaches with such advancement as one of his aims, need be disquieted by any assertions that psychology is against him. Even though he may see no whit of improvement in the pupil's mathematical thinking, or in his ability to handle the subject's more complicated processes, or in his appreciation of its wide range of usefulness, if the teacher succeeds only in giving the pupil such increased familiarity with the most elementary notions of the subject as will enable him with greater speed and accuracy to mark a cross in the square and not in the triangle, and to draw a line from the second circle above the third and below the fourth to the fifth, he may rest content with the knowledge that the best psychologists that the United States Government could summon to its aid will, in consequence of that improvement, rate that pupil higher in general intelligence. 